Matías L. Saidel. Investigador Asistente del Consejo Nacional de Investigaciones Científicas y Técnicas de Argentina - Universidad Católica de Santa Fe. Profesor titular de Filosofía Política en la Facultad de Trabajo Social de la Universidad Nacional de Entre Ríos. Jefe de Trabajos Prácticos de Problemática del Conocimiento en las Ciencias Sociales en la Facultad de Ciencia Política de la Universidad Nacional de Rosario. Sus investigaciones y sus publicaciones han versado fundamentalmente sobre lo común, la biopolítica, el genocidio y la producción de subjetividad en el marco gubernamental neoliberal.

Contacto: matiaslsaidel@gmail.com 


\section{ALGUNAS NOTAS SOBRE NEOEXTRACTIVISMO, (POS)NEOLIBERALISMO Y POPULISMO EN SUDAMÉRICA}

Matías L. Saidel

CONICET - UNER - UNR

\section{SOME NOTES ON}

NEOEXTRACTIVISM,

(POST)NEOLIBERALISM,

\section{AND POPULISM IN SOUTH AMERICA}

DOI: $10.17450 / 150207$

Fecha de recepción 11 de agosto 2015; fecha de aceptación 27 de setiembre 2015. El artículo es fruto de un proyecto de investigación desarrollado en el Consejo Nacional de Investigaciones Científicas y Técnicas de Argentina, Universidad Católica de Santa Fe, en la Universidad Nacional de Entre Ríos y en la Facultad de Ciencia Política de la Universidad Nacional de Rosario.

\section{Resumen}

Este trabajo reflexiona sobre la realidad sociopolítica sudamericana actual teniendo en cuenta tres categorías interrelacionadas: (pos)neoliberalismo, populismo, neoex- 
tractivismo. Señala que la configuración de liderazgos populistas es apenas uno de los aspectos para comprender una etapa posneoliberal signada por un crecimiento económico fuertemente dependiente de prácticas neoextractivistas que llevan a una producción de renta a partir de los bienes comunes - de la cual una parte se redistribuye- y de formas de subjetivación y de gestión influenciadas por la racionalidad gubernamental neoliberal. De allí el carácter precario y ambivalente de los procesos de transformación impulsados por los gobiernos “progresistas” de la región.

\section{Palabras clave}

Posneoliberalismo, populismo, neoextractivismo, neoliberalismo, Sudamérica.

\section{Abstract}

This paper reflects on present-day South-American sociopolitical reality through three intertwined notions: (post)neoliberalism, populism, and neo-extractivism. It points that the configuration of populist leaderships is merely one of the features to understand the post-neoliberal stage, which is characterized by economic growth heavily dependent upon neo-extractivistic practices that lead to a production of rent from common goods, a part of which is destined to redistribution of income, and by forms of subjectivation and management which are influenced by neoliberal governmental rationality. Therefrom derive the precariousness and ambivalence of the transformations that have been driven by South-American "progressive" governments.

\section{Keywords}

Post-neoliberalism, populism, neoextractivism, neoliberalism, South America.

\section{Introducción}

Si hay algo que ha distinguido a Sudamérica en las últimas décadas es su carácter de laboratorio político. Primero, desde los años setenta, ha sido un territorio privilegiado de experimentación de las políticas neoliberales. Después de una década de 1990 en la que se impusieron reformas neoliberales en toda la región, en la primera década y media del s. XXI se configuran una serie de experiencias políticas que intentan revertir 
algunos de esos procesos. Sin embargo, estas nuevas experiencias no están exentas de contradicciones. A nivel político, se ha hablado de nuevas formas de "populismo", signadas por liderazgos fuertes capaces de articular una heterogeneidad de demandas. En el plano económico, si bien el crecimiento de toda la región fue de la mano de una mejora en la distribución del ingreso, la matriz de producción y acumulación condujo a una profundización de la explotación irracional de los recursos naturales, haciendo posible los avances de la mercantilización y la financiarización a sectores anteriormente ajenos a dicha lógica. Por otro lado, los modos de subjetivación que se fueron difundiendo entre distintos sectores sociales están lejos de representar una despedida para la razón gubernamental neoliberal.

Por eso mismo, sería erróneo considerar al neoliberalismo como una ideología o una teoría científica que busca materializarse en la realidad política, como también lo sería tomar sólo algunos indicadores sociales -como los índices de pobreza por ingresospara evaluar el impacto transformador de la era "posneoliberal". A nuestro entender, el neoliberalismo se despliega como una racionalidad gubernamental ${ }^{1}$, es decir, como un conjunto de dispositivos de gobierno que estructuran el campo de acción de los actores sociales, modulando un conjunto de prácticas que se desarrollan cotidianamente y que configuran una forma de vida. En este sentido, la racionalidad neoliberal logra investir los afectos, pasiones y racionalidades que motorizan el accionar de los sujetos, quienes no se limitan a obedecer a una autoridad externa sino que se encuentran deseando, actuando, viviendo y pensando en sintonía con premisas neoliberales.

Con este trasfondo, en lo que sigue intentaremos caracterizar este momento histórico latinoamericano teniendo en cuenta tres categorías interrelacionadas que han sido utilizadas en los últimos años y que nos permitirán establecer un panorama general de la situación: (pos)neoliberalismo, populismo, neoextractivismo.

\section{Neoliberalismo: ¿desde cuándo y hasta dónde?}

El neoliberalismo tuvo un temprano debut en Sudamérica, expandiéndose progresivamente desde que en los años setenta las sanguinarias dictaduras del Cono Sur, con los casos paradigmáticos de Chile y de Argentina, intentaran aplicar un programa consistente en la destrucción del magro Estado social y el combate a las conquistas populares,

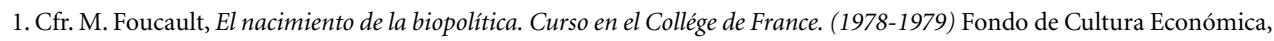
Buenos Aires, 2007. 
buscando abrir los mercados nacionales a la competencia extranjera y financiarizar la economía. La crisis de la deuda, resultante del endeudamiento exponencial de esos años y del alza de las tasas de interés, llevó a varios países a negociaciones en los años ochenta, facilitando la imposición por parte de los organismos multilaterales de crédito de reformas neoliberales de todo tipo. En la mayor parte de los países sudamericanos, los años noventa se caracterizaron por la existencia de gobiernos democráticamente electos que, bajo presión externa e interna, aplicaron las políticas del "Consenso de Washington", cuyo resultado fue el aumento del desempleo, la pobreza y la exclusión social. La movilización social masiva y las luchas que se dieron desde mediados de esa década llevaron al poder a gobiernos que, o bien fueron resultado directo de los movimientos sociales o bien que, llegados al poder, se vieron obligados a tener en cuenta las demandas populares. Ello llevó, desde hace una década y media, a revisar aspectos importantes de las políticas neoliberales, que fueron perdiendo consenso en la ciudadanía. En este marco, si nuestro enfoque se centra en la experiencia política de los países sudamericanos que revisaron sus políticas anteriores, se impone preguntarnos: ¿Por qué hablar de neoliberalismo, hoy? ¿Qué entendemos por este término gastado? ¿No hemos derrotado y destruido a ese monstruo? ¿No hemos conjurado ese fantasma?

Distingamos, por empezar, algunas de las dimensiones que suelen incluirse en la caracterización de los procesos neoliberales y que estuvieron presentes en los años ochenta y noventa en toda la región.

En primer lugar, hay un sentido corriente del término que refiere a la dimensión de las políticas públicas y formas de regulación política y económica, implicando una redefinición de las funciones del Estado -no su "retirada"-, donde su objetivo ha sido instaurar una lógica de la competencia en todos los ámbitos de la existencia, adoptando una racionalidad tecnocrático-empresarial legitimada en la buena governance. ${ }^{2}$ Esta gobernanza, aparentemente aséptica y neutral, implicaba un Estado que se rige en su propio funcionamiento por criterios empresariales de competencia y rendimientos que pueden

\footnotetext{
2. Como señala Marzocca, la noción polisémica de governance juega un rol estratégico al producir, con su aparente pluralización de instancias consultivas y operativas, un "proceso de despolitización de los procesos decisionales y de neutralización técnico-administrativa de los problemas más importantes y graves de nuestra época”. O. Marzocca, Il Governo dell'Ethos. La produzione politica dell'agire economico, Mimesis, Milano-Udine, 2011, p. 18. Esta noción de governance es ampliamente discutida en el primer número de Soft Power en los trabajos de Tucci y Ferrarese. Esta última señala la incompatibilidad entre la governance y los pilares de la democracia representativa moderna, como la referencia al pueblo y al territorio, y al hecho de que si bien se presenta como una forma más inclusiva de gobierno, termina resultando altamente excluyente, signada por una racionalidad económica y tecnocrática. La mayor apertura a la participación de grupos de interés se traduce en la práctica en el favorecimiento de organizaciones con gran capacidad de presión. Esto lleva al abandono de los grandes proyectos en política y a una privatización de la toma de decisiones. Cfr. "Governance: A soft revolution with hard political and legal effects", en Soft Power, 1, 2014, pp. 35-58.
} 
ser evaluados, premiados o castigados. Es en parte esa lógica eficientista la que legitimó en algunos países de Sudamérica -especialmente en Argentina- medidas como las privatizaciones/concesiones -que en algunos casos implicaron la entrega de las empresas estatales a valores irrisorios, en las que el Estado siguió invirtiendo pero ya no controlando directamente-, endeudamiento público con los organismos financieros internacionales y del sector privado cuya meta principal fue garantizar la capacidad de pago de intereses, pago indiscriminado de deuda pública derivada en parte de estatización de deudas privadas, financiarización de las cajas de pensión que pasaron al régimen de capitalización privado, desregulación de los mercados, reformas aduaneras tendientes a la apertura comercial, flexibilización laboral, desindustrialización de la economía para aprovechar "ventajas comparativas y competitivas", aumento de las tasas de explotación y de productividad generando un desempleo sin precedentes, reformas educativas que apuntaron a producir los sujetos necesarios para ese tipo de sociedad sin producción de bienes industriales, naturalización de la pobreza y la desigualdad, etc.

En segundo lugar, el neoliberalismo ha caracterizado el modo en el cual funciona y se organiza el capitalismo global. Los mercados financieros internacionales, las políticas de deslocalización de las empresas, las relaciones entre Estados, las organizaciones internacionales, las organizaciones de comercio internacional, etc., tienen en común el regirse por una lógica de la competencia, la competitividad, la desregulación/liberalización y la gestión por resultados cuantificables. La fase neoliberal de la economía-mundo no puede desligarse de las dinámicas de la globalización o emergencia del imperio, ${ }^{3}$ donde la soberanía nacional se ve minada por redes de poder que, en principio, no tendrían un centro unitario -aunque la ultima ratio de la soberanía, la guerra y la excepción (como así también la hegemonía: "dirección intelectual y moral”) remiten a actores claramente identificables-.

En tercer lugar, tenemos que considerar una variable relacionada con las anteriores: el modelo productivo que adopta una nación, de la cual dependerá en buena medida su papel en la economía global, las relaciones de poder y la estructura social del país. Por citar un ejemplo, en países como Argentina, el dramático proceso de desindustralización, consecuencia de la apertura comercial y la financiarización de la economía

3. M. Hardt, A. Negri, Imperio, Paidós, Barcelona, 2005. Cabe señalar que nos parece sugerente la tesis de una nueva forma de soberanía sin vértice ni centro. Sin embargo, el fin del imperialismo nunca se corroboró empíricamente en América Latina como tampoco en Asia o África. Si bien ahora en la región se favorecen la diplomacia del dólar y los golpes blandos, Estados Unidos y sus aliados siguen interviniendo aquí y allá para desestabilizar gobiernos contrarios a los intereses de sus empresas. Una clásica crítica a Imperio desde Sudamérica fue formulada tempranamente por A. Borón, Imperio \& Imperialismo. Una lectura crítica de Michael Hardt y Antonio Negri, CLACSO, Buenos Aires, 2004. 
fue parte explícita desde los setenta de un proyecto de ataque a las clases populares y al poder obrero y sindical. ${ }^{4}$ En el modelo productivo se volvió progresivamente a la ideología liberal de las ventajas comparativas y se ligaron ideológicamente las ventajas competitivas al costo laboral.

Muchas de estas medidas fueron revertidas en la última década, no tanto en el terreno de la producción como en el de la distribución. Si bien en algunos casos hubo una fuerte recuperación del mercado interno y del sector industrial, en general se avanzó fuertemente en formas de extractivismo y en la reprimarización de las exportaciones. Este es uno de los puntos de mayor continuidad con la fase precedente, pues, en tanto aceleración de la lógica capitalista, el neoliberalismo supone una ultra-explotación de lo común, que además de los bienes que la tradición consideró herencia de la humanidad, remite a los "resultados de la producción social que son necesarios para la interacción social y la producción ulterior, tales como conocimientos, lenguaje, códigos, información, afectos, etc." ${ }^{5}$

\section{(Pos)neoliberalismo y (neo)extractivismo}

En los últimos años hubo en la mayor parte de Sudamérica cierto cuestionamiento a parte del primer y segundo aspecto mencionados en el apartado anterior. Hubo un intento de redistribución de los ingresos generados por las exportaciones que si bien no logró disminuir las desigualdades sociales de manera abrumadora, permitió mitigar situaciones de pobreza y exclusión extremas, acrecentando las clases medias. ${ }^{6}$ Además, se intentó darle un valor nuevo a la integración regional como forma de posicionarse en el contexto capitalista global, llegando a hacer trizas el

4. Véase, por ejemplo, J. Villarreal, "Los hilos sociales del poder", en E. Jozami et al., Crisis de la dictadura argentina, Siglo XXI, Buenos Aires, 1985.

5. M. Hardt, A.Negri, Commonwealth. El proyecto de una revolución del común, Akal, Madrid, 2011, p. 10. De todos modos, habría que puntualizar que lo común no surge espontáneamente en la cooperación social sino que es producto de una praxis y una institución social, y problematizar la tesis de la "expropiación de lo común”, ya que lo común no puede confundirse ni con algo dado "naturalmente" ni con algo exterior al capitalismo. Como señalan Dardot y Laval, las tesis postoperaistas de la expropiación de lo común parecen usar a Proudhon contra Marx. Mientras el primero veía a la cooperación social como una fuerza autónoma cuyo valor la propiedad privada se limitaba a robar, Marx entiende que el capital organiza la cooperación social (subsunción real) y prepara así el terreno de su propia superación. Ahora bien, para los franceses, lejos de observarse una autonomización de la cooperación social, no sólo el capital sigue cumpliendo un rol decisivo sino que lo común es siempre instituido y por eso no puede ser "expropiado". Cfr. P. Dardot, Ch. Laval, Commun. Essai sur la révolution du XXIème siècle, La Découverte, Paris, 2014.

6. Según los datos del banco mundial, la pobreza por ingresos disminuyó en toda la región de manera significativa en la última década y alrededor de 80 millones de personas se incorporaron a las clases medias en América Latina http://povertydata.worldbank.org/poverty/region/LAC. 
proyecto del ALCA y creando instituciones como UNASUR, ALBA, CELAC, Banco del Sur, etc.

Sin embargo, el renovado protagonismo de la intervención estatal en el plano de la redistribución del ingreso, que posibilitó mayores accesos al consumo por parte de algunos sectores castigados por el neoliberalismo salvaje de los años noventa y su crisis, se basó en una estructura productiva que profundizó algunos de los rasgos más nefastos de esa etapa. ${ }^{7}$ Por ello, algunos analistas empezaron a hablar de neoextractivismo o de un extractivismo progresista ${ }^{8}$, ya que si bien la presencia de los sectores extractivos cobra una importancia cada vez mayor en la economía, las lógicas que rigen dichos procesos serían distintas de las anteriores. Es decir, a diferencia de lo que sucedía en los ochenta y noventa, donde el Estado transfería al sector privado la explotación de los recursos naturales con una fuerte transnacionalización del sector extractivo, en el neoextractivismo, no sólo "el Estado es mucho más activo, con reglas más claras” sino que además tiene otros objetivos. De todos modos, la gestión estatal de los recursos naturales no ha llevado a cambiar las "estrategias empresariales basadas en la competitividad, reducción de costos y aumento de la rentabilidad [...] bajo criterios de eficiencia clásicos, incluyendo la externalización de impactos sociales y ambientales" ${ }^{10}$

En este marco, se asistió en la última década a una reprimarización de las exportaciones, representando la exportación de commodities la fuente más importante de divisas de la región. ${ }^{11}$ Esto implica un elemento de fragilidad de la sustentabilidad económica de estos procesos, dada la fluctuación a la que puede verse sometida la demanda y los precios de dichos productos, totalmente dependientes de los mercados financieros globales. ${ }^{12}$ Pero mucho más dramática es la insustentabilidad ecológica y social de los nuevos procesos de sobreexplotación de los recursos naturales. No sólo casos como los de la minería a cielo abierto, que contaminan el agua de la que se nutren pobladores y producciones agrícolas, o del petróleo y el gas, que con técnicas como el fracking

\footnotetext{
7. Cabe notar que en países neoliberales como Colombia, Chile y Perú, el extractivismo no necesariamente implicó el apoyo a políticas redistributivas.

8. E. Gudynas, "El nuevo extractivismo progresista en América del sur: tesis sobre un viejo problema bajo nuevas expresiones", en A. Acosta et al, Colonialismos del siglo XXI. Negocios extractivos y defensa del territorio en América Latina, Icaria, Barcelona, 2011, pp. 75-92; E. Lander "El neoextractivismo como modelo de desarrollo en América Latina y sus contradicciones", trabajo presentado en (Neo)Extractivismo y el futuro de la democracia en América Latina: diagnóstico y retos, Heinrich Böll Stiftung, Berlín 13-14 de mayo 2014. Disponible en http://mx.boell.org/sites/default/files/edgardolander.pdf 9. E. Gudynas, "El nuevo extractivismo progresista en América del Sur".

10. Ibid., p. 82.

11. En este sentido, M. Svampa señala que se pasó del Consenso de Washington al consenso de los commodities. Cfr. “'Consenso de los Commodities' y lenguajes de valoración en América Latina”, en Nueva Sociedad, 244, marzo-abril de 2013, pp.30-46.

12. De hecho, la retracción de la demanda china y la caída de los precios de los commodities tuvo efectos directos e indirectos en la desaceleración y estancamiento de las economías argentina, venezolana y brasilera de los últimos dos años.
} 
amenazan con contaminar regiones enteras, sino también la expansión indiscriminada de la frontera agrícola mediante el monocultivo de soja transgénica, lo cual implicó la deforestación masiva de los bosques nativos en varios países del Cono Sur, la contaminación de pueblos enteros con agrotóxicos como el glifosato, aumentando exponencialmente las tasas de cáncer, la pérdida de biodiversidad, las inundaciones producto de la deforestación y la expulsión de población rural, entre otras cosas. Este proceso es particularmente inquietante en la Argentina que ha sufrido un proceso inédito de desertificación en las últimas dos décadas. De este modo, se produce un flujo financiero que en parte se redistribuye a través de impuestos, regalías, o derechos de exportación, pero, al mismo tiempo, vastos sectores de la sociedad, especialmente la población campesina, sufren la expulsión y el desarraigo consiguientes.

De hecho, allí radica no solo una contradicción importante de los nuevos gobiernos progresistas sino también una retroalimentación de legitimidad tanto para esos propios gobiernos como para las políticas extractivas. ${ }^{13}$ Es decir, dado que en buena medida estos gobiernos legitiman el extractivismo en el hecho de que los recursos así generados permiten atender a la redistribución de la riqueza y acceso a necesidades básicas para los sectores más pobres, cuestionar el extractivismo supondría cuestionar, según los gobiernos, las políticas de redistribución y de desarrollo social. Por otro lado, estos gobiernos se presentan como los únicos capaces de garantizar que los recursos así extraídos contribuyan al desarrollo económico y social de sus países y no sólo a empresas multinacionales que giran sus dividendos al exterior. Tanto E. Morales y A. García Linera en Bolivia como R. Correa en Ecuador han expresado repetidamente que la extracción de gas, petróleo, minerales, etc. son indispensables para transitar hacia una sociedad capaz de generar un modelo productivo alternativo, en tanto que la expropiación del 51\% del capital accionario de YPF en Argentina se hizo con la promesa de priorizar la rentabilidad financiera de la empresa. En este sentido, la apuesta ecuatoriana por la economía del conocimiento -bío y nanotecnologías- o la fuerte inversión de Argentina en ciencia y técnica y educación pública tienen sus condiciones de posibilidad en la explotación de los recursos primarios que permitan financiar dicha transición en un marco de estabilidad social. ${ }^{14}$

13. Lander, "El neoextractivismo como modelo de desarrollo en América Latina y sus contradicciones".

14. Como señalan Mezzadra y Brighenti, las mayores inversiones en cultura, investigación y circulación de saberes permiten comprender la ruptura de formas anteriores de acumulación y la transición a un modelo de governance post-neoliberal. S. Mezzadra, M. Brighenti, "Il laboratorio politico latinoamericano. Crisi del neoliberalismo, movimenti sociali e nuove esperienze di governance”, in M. Baldassari, D. Melegari (eds.), Populismo e democrazia radicale. In dialogo con Ernesto Laclau, Ombre corte, Verona 2012. 
Por lo demás, todo lo anterior se dio en el marco de una aceptación de la institucionalidad liberal global, una competencia entre Estados de la región por atraer inversores y socios comerciales, y una inserción subordinada en la economía mundial, donde se genera una fuerte dependencia de potencias como China, privilegiada como fuente de divisas, por sobre el comercio intracontintental.

Estas contradicciones muestran que la nueva izquierda latinoamericana está conformada por auténticos gobiernos progresistas o neodesarrollistas que, más allá de los artículos constitucionales sobre el Buen Vivir, el derecho a un ambiente sano y los derechos de los pueblos originarios, y de encendidos discursos sobre desarrollo sustentable, ponen el crecimiento económico como su objetivo primero y aprovechan que, al menos en esta década, los términos del intercambio mejoraron para los commodities -aunque, en algunos $\operatorname{casos}^{15}$, tampoco descuidan la tradicional propuesta de industrializar la economía-. ${ }^{16}$ El sector primario aparece así como llave maestra para el crecimiento económico y éste como la conditio sine qua non para el desarrollo social y en última instancia, el Buen Vivir. ${ }^{17}$

Ahora bien, esta lógica asume así dos postulados básicos del capitalismo neoliberal que generan efectos al menos en principio no deseados: la primacía de la competitividad y del enriquecimiento y, en ese marco, el aprovechamiento de las ventajas comparativas de cada nación en la división internacional del trabajo. En última instancia, los recursos naturales, aunque con mayor control del Estado, siguen siendo entendidos como un capital fijo capaz de generar flujos de renta potencial o actual. No se pone en cuestión la rentificación o mercantilización de los bienes comunes sino que esta es legitimada por la redistribución de la plusvalía obtenida. ${ }^{18}$ Así, lo que se legitima en última instancia es

15. El caso venezolano es paradójico puesto que si bien la renta petrolera permitió modificar en buena medida la distribución de recursos y derechos, la estructura productiva del país no puede garantizar la soberanía económica; de hecho, el país debe importar gran cantidad de artículos básicos -incluso alimentos- que no produce.

16. El desarrollismo clásico advertía que los términos del intercambio de las exportaciones primarias se deterioraban sistemáticamente frente al precio de los bienes industriales, que tenían mayor valor agregado. De allí la propuesta de sustitución de importaciones que fue implementada desde los años treinta y cuarenta en distintos países latinoamericanos y recuperada en la última década en países como Argentina.

17. Esta posición, que defiende la necesidad de aprovechar la explotación de los recursos no renovables en pos del desarrollo, ha sido asumida oficialmente en la XII cumbre del ALBA (Alianza Bolivariana para los Pueblos de Nuestra América) de 2013 celebrada en Guayaquil.

18. Como señala M. Svampa, "la hipótesis de máxima apunta al retorno de un Estado moderadamente regulador, capaz de instalarse en un espacio de geometría variable, esto es, en un esquema multiactoral [...] pero en estrecha asociación con los capitales privados multinacionales, cuyo peso en las economías nacionales es cada vez mayor. Ello coloca límites claros a la acción del Estado nacional, y un umbral inexorable a la propia demanda de democratización de las decisiones colectivas por parte de las comunidades y poblaciones afectadas por los grandes proyectos extractivos. Tampoco hay que olvidar que el retorno del Estado en sus funciones redistributivas se afianza sobre un tejido social muy vulnerable, lo que fue acentuado por las transformaciones de los años neoliberales, y que las actuales políticas sociales se presentan en muchos casos en continuidad -abierta o solapada- con aquellas políticas compensatorias difundidas en los años noventa mediante las recetas del Banco Mundial”. (“'Consenso de los Commodities' y lenguajes de valoración en América Latina”, p. 38). 
la lógica rentística como tal ${ }^{19}$, pues lo que está en discusión no es la primacía de la renta ni cómo se la genera, sino quién se la apropia. ${ }^{20}$

En este sentido, estas políticas macroeconómicas, que intentan dejar atrás el neoliberalismo de los noventa, se configuran como una especie de pharmakon. Por un lado, permiten mejorar la "calidad de vida" de sectores otrora marginados a través del acceso a mayores consumos. Por otro, habilitan la extensión de las lógicas neoliberales a toda la sociedad, desde el punto de vista de la primacía de las finanzas y la renta, la competitividad necesaria para la supervivencia, la inclusión de más y más población en las lógicas mercantiles y en la extensión de las expectativas de consumo con los efectos consiguientes sobre el estilo de vida deseable. Es decir, que la ramificación de la lógica de la capitalización y empresarialización de la subjetividad (ver infra) no puede desligarse del contexto macroeconómico signado por la financiarización y el neoextractivismo. En este marco, insistimos en que no debe descuidarse el rol que las expectativas de consumo y el endeudamiento consiguiente tienen en la necesidad de adoptar estrategias empresariales de conducta. Como sostiene Lazzarato, junto con la producción de renta para los acreedores, la deuda produce al hombre endeudado, quien sería la otra cara del empresario de sí mismo, y esto se da tanto para el caso de las hipotecas en el primer mundo como en el de microcréditos en el tercero. Así, este aspecto "democrático" e inclusivo de políticas compatibles con la racionalidad neoliberal da lugar a la extensión de una lógica gubernamental que va más allá de la "acumulación por desposesión" (Harvey), con la cual se suele caracterizar al extractivismo, ${ }^{21}$ para referirse a "una acumulación por subordinación extendida y profunda de todos los elementos de la vida de la población".22

\footnotetext{
19. Si bien abundan los análisis de cómo en el capitalismo actual todo ingreso se transforma en una renta, consideramos erróneo que se pueda pensar un cambio sustancial sólo desde el terreno de la distribución.

20. Esto mismo fue reconocido por Chávez en el programa de gobierno presentado para las elecciones presidenciales de 2012: "Nuestra política petrolera debe ser revolucionaria, lo cual tiene que ver con quién captura la renta petrolera, el cómo se capta y cómo se distribuye. No cabe duda que debe ser el Estado quien controle y capture la renta petrolera, con base en mecanismos que maximicen su valor, para distribuirla en beneficio del pueblo, procurando el desarrollo social integral del país, en condiciones más justas y equitativas. Este es el elemento que nos diferencia de cualquier otra política petrolera”. Hugo Chávez, "Propuesta del Candidato de la Patria Comandante Hugo Chávez para la Gestión Bolivariana Socialista 2013-2019”. Programa de Gobierno presentado por Hugo Chávez, Caracas, 11 de junio 2012, en E. Lander, "El neoextractivismo como modelo de desarrollo en América Latina y sus contradicciones".

21. Cfr. J. Seoane, "Neoliberalismo y ofensiva extractivista. Actualidad de la acumulación por despojo, desafíos de Nuestra América”, en Theomai, segundo semestre de 2012, 26, disponible en http://revista-theomai.unq.edu.ar/NUMERO\%2026/ Seoane\%20-\%20Ofensiva\%20extractivista.pdf

22. P. Dardot, Ch. Laval, Commun, p. 219. Citamos en extenso este pasaje que resume esta idea: "En instillant toujours plus de concurrence dans les rouages sociaux, en adaptant les différentes sphères sociales et politiques à la nouvelle norme générale de la compétitivité, les politiques néolibérales travaillent à mettre en phase de plus en plus étroitement la reproduction de la société et la reproduction du capital. [...] En somme, ce n'est pas tant de dépossession comme mode d'accumulation spécifique qu'il faudrait parler, mais de production continue des conditions sociales, culturelles, politiques et subjectives d'élargissement de l'accumulation du capital, ou encore de devenir-monde du capital par le moyen de la gouvernementalité
} 
En este sentido, el posneoliberalismo extiende algunas de las lógicas mercantiles que el neoliberalismo salvaje, que transformó al viejo ejército industrial de reserva en masa marginal, no podía producir. ${ }^{23}$ Quizá la racionalidad neoliberal tolere bien el avance de la desigualdad social pero no tanto que existan seres humanos que puedan vivir totalmente al margen del mercado, y que sean "demasiado pobres para la deuda". ${ }^{24}$ En efecto, las políticas de inclusión social de los gobiernos progresistas no serían necesariamente contrarias en sus efectos a la razón gubernamental neoliberal, pues, en general, además de garantizar condiciones mínimas de supervivencia, buscan incluir a través del consumo y el trabajo, fomentando ciertas capacidades y prácticas, cierto capital humano, que el mercado necesita para su desarrollo.

\section{La racionalidad (pos)neoliberal como forma de vida}

Hasta aquí nos hemos referido centralmente a dimensiones macrosociales y macroeconómicas que están directamente ligadas a los modos en que corrientemente se entendió al capitalismo neoliberal. Sin embargo, en tanto racionalidad gubernamental, el neoliberalismo tiene un rol central en la producción de subjetividad, de sentidos, de mundo, trascendiendo el ámbito de las políticas públicas. El neoliberalismo es ante todo una tecnología de gobierno que intenta crear las condiciones de una auto-gestión y auto-vigilancia que permitan a los sujetos desenvolverse en un mercado que debe ser organizado desde el Estado. En efecto, el neoliberalismo supone generar los marcos para que pueda desplegarse la ética del empresario de sí mismo. ${ }^{25}$ Como sostienen Dardot y Laval: "La racionalidad neoliberal tiene como característica principal la generalización de la competencia como norma de conducta y de la empresa como modelo de subjetivación... El neoliberalismo es la razón del capitalismo contemporáneo [...] se puede definir como el conjunto de los discursos, de las prácticas, de los dispositivos que determinan un nuevo modo de gobierno de los hombres según el principio universal de la competencia”. ${ }^{26}$

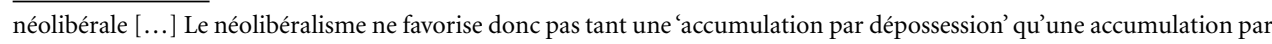
subordination élargie et approfondie de tous les éléments de la vie de la population [...]".

23. José Nun propone dicho concepto en 1969 y lo retoma en el artículo de 1999: "El futuro del empleo y la tesis de la masa marginal", en Desarrollo Económico - Revista de Ciencias Sociales. Ides, vol. 38, 152, enero-marzo 1999, pp. 985-1004. 24. G. Deleuze, "Posdata sobre las sociedades de control”, en C. Ferrer (ed.) El lenguaje literario, 2 tomo, Ed. Nordan, Montevideo, 1991.

25. Cfr. M. Foucault, El nacimiento de la biopolítica; M. Lazzarato, La fábrica del hombre endeudado. Ensayo sobre la condición neoliberal, Amorrortu, Buenos Aires, 2013; Id. Il governo dell'uomo indebitato, DeriveApprodi, Roma, 2013.

26. Cfr. P. Dardot, Ch. Laval, La nueva razón del mundo, ensayo sobre la sociedad neoliberal, Gedisa, Barcelona, 2013 p. 15. 
Entender al neoliberalismo como racionalidad gubernamental permite, primero, refutar la idea de una retirada del Estado. Son los Estados los que "han introducido y universalizado en la economía, en la sociedad y hasta en su propio seno, la lógica de la competencia y el modelo de la empresa". ${ }^{27}$ En segundo lugar, permite destacar el carácter transversal de los modos de poder ejercidos en una sociedad en una misma época, ya que el neoliberalismo lleva su lógica a todos los ámbitos de la existencia. En resumen, considerado como racionalidad gubernamental, el neoliberalismo es precisamente el despliegue de la competencia mercantil como lógica normativa generalizada, desde el Estado hasta lo más íntimo de la subjetividad. ${ }^{28}$

En este sentido, estos enfoques permiten comprender mejor ciertas continuidades en el marco de la discontinuidad, puesto que la autoempresarialidad y la competición son lógicas que habitan las prácticas cotidianas de sujetos ubicados en distintos estratos de la sociedad. De allí la relación de complementariedad entre ciertas políticas macroeconómicas que cuestionan aspectos de la dogmática neoliberal con las formas neoliberales de configuración de subjetividades.

En ese sentido, Verónica Gago distingue un "neoliberalismo desde arriba" y otro "desde abajo". ${ }^{29}$ Con la primera categoría se refiere a las macropolíticas impulsadas por los organismos internacionales y las grandes potencias económicas que se impusieron en América Latina durante los años ochenta y noventa, y que actualmente "la Troika" impone en Europa. Como vimos, este ciclo "desde arriba” encontraría ciertos límites en la última década y media, desde el ascenso al poder de Chávez en Venezuela, seguido por los cambios políticos que se dieron fundamentalmente en Ecuador, Bolivia, Argentina, Uruguay, y Brasil. Como ya mencionamos, estos gobiernos "progresistas", algunos de izquierda y otros de centro-izquierda, impulsaron políticas de crecimiento económico y redistribución de riqueza hacia sectores expulsados del mercado y de la ciudadanía en las décadas anteriores, generándose una inclusión social a través del consumo.

Por neoliberalismo desde abajo, Gago entiende un conjunto de "condiciones sobre las que opera una red de prácticas y saberes que asume el cálculo como matriz subjetiva primordial y que funciona como motor de una poderosa economía popular que mixtura saberes comunitarios autogestivos e intimidad con el saber-hacer en la crisis como tecnología de una autoempresarialidad de masas”. El neoliberalismo arraigaría así en la "pragmática vitalista" de los sectores populares, ${ }^{30}$ que desarrollan sus propias estrategias

\footnotetext{
27. Ibid., p. 17.

28. Ibid., p. 25.

29. V. Gago, La razón neoliberal. Economías barrocas y pragmática popular, Tinta Limón, Buenos Aires, 2014. 30. Ibid., p. 12.
} 
de empresarialización, en el marco del auge de nuevas posibilidades de consumo y nuevas formas de explotación.

En este sentido, si "desde arriba" el neoliberalismo da cuenta de modificaciones en el régimen de acumulación y en las instituciones macrosociales, "desde abajo" puede ser pensado como una forma de vida. ${ }^{31}$ Si por arriba el neoliberalismo sobrevive en la renovación de las formas extractivas y desposesivas, por abajo se da como una racionalidad que negocia beneficios en ese contexto de desposesión, mezclando servidumbre y conflictividad. Por eso, para Gago, hablar de "posneoliberalismo" no implicaría una superación del neoliberalismo sino un modo de caracterizar su pérdida de legitimidad como política estatal a partir de las revueltas sociales de la última década, las mutaciones en el capitalismo global a partir de su crisis, lo cual coexiste con la persistencia de "algunas de sus premisas fundamentales en la acción popular que lo ha impugnado".32

En este sentido, la norma de conducta empresarial ha sido adoptada paulatinamente no sólo por los sectores incluidos en el mercado laboral formal sino también por los sectores informales que surgieron a la luz de la globalización neoliberal y que han ido desarrollando estrategias de supervivencia novedosas en el contexto "posneoliberal". Es decir, que además de contribuir a entender cierta capacidad de persistencia y de renovación de lógicas neoliberales, este tipo de estudios de la economía popular, de los sectores que no están plenamente incluidos en la ciudadanía, muestran la transversalidad de las lógicas neoliberales a distintos sectores de la sociedad.

Pero así como no se puede desligar este neoliberalismo desde debajo de las condiciones macroeconómicas, tampoco se pueden obviar aquellas condiciones macropolíticas en las que se inserta. Respecto de esto último, se ha insistido en la categoría de populismo para caracterizar las lógicas políticas de estos nuevos regímenes progresistas. Veamos qué se entiende por ella y hasta dónde nos sirve para entender los procesos que venimos analizando.

\section{Populismos sudamericanos y (post)neoliberalismo}

A nivel político, se ha intentado caracterizar a estos gobiernos que llevaron a cabo las transformaciones post-neoliberales como populistas. Como sabemos, este calificativo fue usado despectivamente durante la mayor parte del último siglo en Occidente, 
especialmente por los defensores del orden liberal, ${ }^{33}$ desde el propio nacimiento de la sociedad de masas y de los partidos políticos modernos. Las masas populares "irracionales" y "sugestionables" sólo podían producir la destrucción de las instituciones que, como el parlamento, debían ser espacios de discusión reservados a las élites ilustradas. Fue con este esquema leboniano y "elitista" ${ }^{34}$ que se leyó en general al populismo, incluso en sectores de la izquierda, hasta hace muy poco. ${ }^{35}$

Sin embargo, el populismo aparece bajo otra luz en las últimas décadas, y cobra nuevo impulso a nivel teórico-político con discusiones como las planteadas por Ernesto Laclau, quien no casualmente se transformara en una referencia teórica importante para muchos de los gobiernos sudamericanos y para quienes buscaban comprender las lógicas de construcción política que los sostenían. En los años setenta, Laclau entendía al populismo a partir de lógica de interpelación al "pueblo" como antagónico a los poderes dominantes. Tres décadas más tarde, el populismo pasa a ser entendido como una lógica política de constitución de identidades sociales o incluso como la forma de la política tout court. El populismo designa así la construcción de una hegemonía política, consistente en la articulación por parte de un elemento particular que ocupa/ encarna contingentemente el lugar de la universalidad de una cadena equivalencial de demandas que pueden confluir en su oposición a un Otro y en el investimento afectivo de un significante vacío. Esta articulación es absolutamente contingente, políticamente producida, pues surge de un sistema de diferencias sin elementos positivos. ${ }^{36}$ Es decir,

33. Aunque no se deben olvidar los orígenes del populismo, el narodnichestvo ruso, que cumplió un rol importante en el camino hacia la revolución bolchevique y el populismo de los farmers estadounidenses de fines del XIX, expresado en el Partido del Pueblo (1891-1908). Sobre el origen ruso del populismo, cabe destacar el ya clásico y monumental trabajo de F. Venturi, Il populismo russo, Einaudi, Torino, 1952. También cfr. para el caso estadunidense en relación a nuestro marco teórico E. Laclau, Política e ideología en la teoría marxista. Capitalismo, fascismo, populismo, Siglo XXI, Madrid, 1977 e Id. La razón populista, FCE, Buenos Aires, 2005.

34. Con elitismo nos referimos no sólo a una postura política sino a las teorías de las élites elaboradas por autores como Mosca, Pareto y Michels entre 1880 y 1920.

35. Desde una posición socialdemócrata, en el primer número de esta revista, Innerarity reproduce este esquema planteando una alternativa tajante a la que nos veríamos sometidos: "Continuamente estamos obligados a elegir entre racionalidad y populismo", asociando este término a promesas vacías de cumplir aquello que el pueblo demanda, poniendo en riesgo las instituciones, en suma, a las formas plebiscitarias de democracia. Para este autor, que sostiene que los movimientos de protesta en general y los de "la multitud" en particular tienen efectos despolitizadores, habría que proteger a la democracia representativa e indirecta "frente a la ciudadanía, contra su inmadurez, incertidumbre e impaciencia". Cfr. D. Innenarity. Democracia sin política. ¿Por qué la democracia puede perjudicar seriamente a la democracia?”, en Soft Power., 1, enero-junio, 2014. Nos parece que este tipo de afirmaciones no se aplican al menos a los casos aquí estudiados y quizá eso se deba a la ambigüedad del término populismo. En Sudamérica, ni los movimientos de protesta fueron estériles políticamente ni el populismo implicó el fin de la democracia representativa. En todo caso, los populismos lograron representar a sectores anteriormente al margen de la ciudadanía, a esa plebs que el populus (neo)liberal busca aún excluir de la política. Por lo demás, en el caso europeo no parece que el problema sea el exceso de participación ciudadana sino la eliminación de la política democrática por parte de la tecnocracia. El caso griego muestra un gobierno que canalizó las demandas de la movilización popular contra la "austeridad" y donde el reciente voto por el 'No', en el referéndum convocado por Tsipras, muestra la complementariedad posible entre democracia representativa y participación popular.

36. Esta es, más o menos, la definición saussureana de la lengua. 
la articulación política no pasa por identidades preestablecidas sino que reconfigura las identidades diferenciales a partir de distintas demandas sociales. Al mismo tiempo, no hay demandas ni sectores de la realidad que tengan una primacía ontológica para definir las líneas del conflicto político. Por eso el pueblo no es algo dado sino construido políticamente, equivalencial y hegemónicamente. Sin embargo, el significante vacío -justicia, democracia, igualdad, etc.- que puede ser significado de distintas maneras, es pasible de ser hegemonizado por nombres propios. Laclau le otorga un rol decisivo al afecto y a la nominación que constituye retroactivamente aquello que nombra a la hora de conformar una hegemonía política, y la fortaleza y aparente insustituibilidad de los líderes populares latinoamericanos parecerían conformar dicha intuición.

De todos modos, en la lectura laclausiana, el momento populista por excelencia es el de ruptura con el régimen precedente, en el que la multiplicidad de demandas se concentra en un punto nodal y se genera una bipartición del espacio social. Cuando un régimen ya no logra satisfacer las demandas sociales de manera individualizada, las demandas insatisfechas se van acumulando hasta poder confluir en una ruptura populista. La génesis de los nuevos populismos latinoamericanos estaría así en la cantidad de demandas heterogéneas entre sí que las políticas neoliberales no podían satisfacer. Los ciclos de protesta social conjugados con el colapso económico llevaron a la destitución de los regímenes precedentes e hicieron necesario que los nuevos liderazgos tomaran en cuenta dichas demandas, lográndose, al decir del propio Laclau, cierto equilibrio "ente las lógicas equivalenciales (la movilización autónoma de las masas) y las lógicas diferenciales (la absorción institucional de las demandas)". ${ }^{37}$

Cabe señalar que, como sostiene el propio Laclau, dicha lógica puede valer, a priori, para cualquier tipo de política, y de hecho, en Europa la categoría populismo se utiliza de manera casi exclusiva para caracterizar a movimientos que articulan una cadena de equivalencias que amalgama los resentimientos populares mediante un discurso ultranacionalista y xenófobo.

Por otro lado, al describir dicho entramado en términos de hegemonía y articulación de demandas, se está en un terreno donde lo político, en tanto momento instituyente de lo social, ya no puede ser visto como secundario. Probablemente, esto también tuvo que ver con el éxito de dicho marco interpretativo en un momento donde había fracasado estrepitosamente la idea de que el Estado debía limitarse a ofrecer las garantías jurídicas para que el mercado funcionase de manera autónoma. De allí que el ascenso

37. E. Laclau, “Consideraciones sobre el populismo latinoamericano", en Cuadernos del Cendes, 62, Tercera Época, mayo a agosto, 2006. 
de los nuevos gobiernos "progresistas" haya sido visto como una revalorización de "la política" frente a "la economía", dando impulso a políticas que buscaron afirmar la soberanía económica de los Estados, fortalecer el mercado interno, recuperar la producción industrial y redistribuir el ingreso.

Sin embargo, como vimos, las cosas son más complejas. Por un lado, el desarrollo económico que se dio en Latinoamérica no fue muy lejos en el cuestionamiento de los modos de producción y acumulación vigentes. Su punto fuerte estuvo en que al menos la renta generada por las formas extractivas de acumulación se distribuyeran de manera más equitativa. Por otro lado, si entendemos al neoliberalismo como racionalidad gubernamental, podemos decir que el fin de las políticas macroeconómicas que habían sido impuestas por el "consenso de Washington" no implicó el fin del neoliberalismo, puesto que la racionalidad neoliberal ha arraigado en las formas de sentir, pensar y desear de diversos actores sociales, incluso de quienes fueron excluidos violentamente del mercado laboral y de la ciudadanía y luego incluidos mediante el consumo y el trabajo precario. ${ }^{38}$

Volviendo al plano de lo político-institucional, sería reduccionista caracterizar al "populismo sudamericano" sólo en los términos formales de Laclau, pues dejaría de lado la innovación introducida por muchos de los regímenes políticos en cuestión. Sobre todo en los casos de Bolivia, Ecuador y Venezuela, se crearon instituciones revolucionarias tendientes a producir una democracia más participativa y se generaron normas constitucionales que reconocen la plurinacionalidad de dichos pueblos, el respeto por el medioambiente y mecanismos que abren la posibilidad de prolongar mandatos pero también revocarlos mediante dispositivos de democracia directa. Se generó así una vía democrática al socialismo, impensable unas décadas atrás. Sin embargo, no deja de ser un terreno de contradicciones, puesto que al mismo tiempo que se fomentaba la democracia participativa de base, se imponía progresivamente una concentración de poder inédita en las presidencias. No casualmente, los líderes que encarnaron dichos procesos parecen volverse irreemplazables, so pena de detener las transformaciones impulsadas. En este sentido, el populismo, en tanto lógica hegemónica y articulatoria, puede ser pensado como condición de posibilidad de dichas transformaciones y a la vez como una limitante ${ }^{39}$.

\footnotetext{
38. Según algunas estadísticas, en esta etapa "posneoliberal” habrían salido de la pobreza (menos de 4 dólares de ingreso diario) entre 56 y 80 millones de personas en América Latina, aunque la desigualdad no se redujo. Cfr. Informe sobre Desarrollo Humano 2014 del PNUD “Sostener el Progreso Humano: Reducir vulnerabilidades y construir resiliencia”, en http://ep00.epimg.net/descargables/2014/08/28/27a1511518e75cbab284890fe7d226da.pdf e informe del Banco Mundial del 1/10/2014 en http://www.bancomundial.org/es/region/lac/overview\#1

39. Si bien aquí nos limitamos a Sudamérica, la experiencia más significativa en lo que hace a invención de instituciones de autogobierno se dio en el régimen zapatista de Chiapas, aunque su alcance geográfico es limitado. En este sentido, son
} 
En resumen, el marco interpretativo del populismo permitió comprender la constitución de nuevos liderazgos estables a partir de movimientos sociales muy heterogéneos cuyas demandas debieron tener muy en cuenta. Pero esta lógica política no alcanza a discernir por sí misma en qué medida, a nivel macroeconómico y a nivel subjetivo, el capitalismo neoliberal logra sobrevivir, puesto que ni siquiera está en condiciones de tematizarlo. $^{40}$

\section{A modo de cierre}

Como vimos, el marco interpretativo del populismo nos permite caracterizar la ruptura política con los regímenes precedentes a partir de una cantidad de demandas insatisfechas que los nuevos liderazgos supieron articular. Dicho paradigma teórico nos permite comprender especialmente el momento de constitución simbólica del pueblo frente a las oligarquías neoliberales y la erección de nuevos liderazgos que se han vuelto muy sólidos, pero poco nos puede ofrecer para comprender las formas de gestión de lo público que se fueron suscitando y los horizontes de expectativas fuertemente ligados al consumo y a la (auto)empresarialidad que habitan las nuevas subjetividades. Por eso, para caracterizar los procesos que se vienen dando en Sudamérica y evaluar sus impactos se hizo necesario analizar las continuidades y rupturas con el neoliberalismo salvaje de los años noventa, en los aspectos políticos, económicos y sociales.

Hemos mencionado que hay un nuevo protagonismo del sector público en la economía no sólo en el terreno de la producción sino especialmente de la distribución, permitiendo incluir a sectores que habían sido fuertemente castigados en las décadas precedentes y reducir la pobreza. Pero también vimos que las lógicas de la gestión, los modelos de negocios y las formas de inserción internacional no han cambiado significativamente, y que el crecimiento económico se debió en gran medida a las exportaciones de commodities, obtenidas mediante una explotación insustentable de los bienes naturales de los distintos países.

También hemos mencionado que, a nivel subjetivo, la racionalidad neoliberal no ha dejado de impregnar las prácticas cotidianas y las estrategias de supervivencia. No sólo

\footnotetext{
interesantes los trabajos de J. Baschet, Adiós al capitalismo. Autonomía, sociedades del buen vivir y mutiplicidad de mundos, Futuro Anterior, Buenos Aires, 2014.

40. Es por eso que para comprender estos procesos más allá de la lógica discursiva, teniendo en cuenta las prácticas de producción y gobierno, Mezzadra habla de "governance post-neoliberal". Cfr. S. Mezzadra, M. Brighenti, "Il laboratorio politico latinoamericano".
} 
los sectores incluidos en el empleo formal, sino también los más precarios y pobres de la sociedad desarrollan estrategias empresariales con las cuales salir adelante en el marco de un mercado fragmentado en distintos estratos y un Estado que, si bien ya no es prescindente, sigue sometido a los avatares del mercado mundial y a la necesidad de divisas para financiar el crecimiento que, a su vez, se presenta como un objetivo primordial.

En este marco, si hay un elemento común a la producción de valor, distribución de ingreso y formas de subjetivación, es la primacía de la renta. En algunos casos se ha cambiado un tipo de renta por otro, se han modificado relaciones de propiedad y formas de distribución, pero también se ha avanzado en la financiarización de la economía y de la vida cotidiana.

En última instancia, es ésta lógica la que, más allá en los cambios que se dieron en el estilo de gestión y protagonismo del Estado, conecta los grandes proyectos macroeconómicos con el devenir empresa de la subjetividad. Es por eso que ni el neoliberalismo ni el extractivismo pueden ser comprendidos plenamente si no se los pone en relación con la hegemonía del capital financiero globalizado que, desde hace cuatro décadas, impone sus condiciones sobre gobiernos y poblaciones.

Por eso mismo, los alcances emancipatorios de la era posneoliberal en Sudamérica dependerán de la capacidad de los movimientos sociales y de los gobiernos de hacer frente a los desafíos que el capital financiero suscita tanto a nivel macro como micro, y de inventar un nuevo tipo de gubernamentalidad. Resta mucho por recorrer aún, y ya se ciernen en el horizonte, amenazantes, los nubarrones del retorno neoconservador. 